\title{
Article \\ Wide Bandwidth Silicon Nitride Strip-Loaded Grating Coupler on Lithium Niobate Thin Film
}

\author{
Fan Yang ${ }^{1}$, Hong Fang ${ }^{1}$, Huangpu Han ${ }^{2,3, *}$ and Bingxi Xiang 4 (D) \\ 1 School of Sciences, Xi'an Technological University, Xi'an 710021, China; yanfang@st.xatu.edu.cn (F.Y.); \\ fanghong@xatu.edu.cn (H.F.) \\ 2 Zibo Vocational Institute, School of Intelligent Manufacturing, Zibo 255314, China \\ 3 School of Physics, Shandong University, Jinan 250100, China \\ 4 College of New Materials and New Energies, Shenzhen Technology University, Shenzhen 518118, China; \\ xiangbingxi@sztu.edu.cn \\ * Correspondence: 12077@zbvc.edu.cn; Tel.: +86-17865913058
}

check for updates

Citation: Yang, F.; Fang, H.; Han, H.; Xiang, B. Wide Bandwidth Silicon Nitride Strip-Loaded Grating Coupler on Lithium Niobate Thin Film. Crystals 2022, 12, 70. https: / /doi.org/10.3390/ cryst 12010070

Academic Editors: Evgeniy N. Mokhov and Dah-Shyang Tsai

Received: 18 November 2021 Accepted: 31 December 2021 Published: 5 January 2022

Publisher's Note: MDPI stays neutral with regard to jurisdictional claims in published maps and institutional affiliations.

Copyright: (C) 2022 by the authors. Licensee MDPI, Basel, Switzerland. This article is an open access article distributed under the terms and conditions of the Creative Commons Attribution (CC BY) license (https:// creativecommons.org/licenses/by/ $4.0 /)$.

\begin{abstract}
In this research, a vertical silicon nitride strip-loaded grating coupler on lithium niobate thin film was proposed, designed, and simulated. In order to improve the coupling efficiency and bandwidth, the parameters such as the $\mathrm{SiO}_{2}$ cladding layer thickness, grating period, duty cycle, fiber position, and fiber angle were optimized and analyzed. The alignment tolerances of the grating coupler parameters were also calculated. The maximum coupling efficiency and the $-3 \mathrm{~dB}$ bandwidth were optimized to $33.5 \%$ and $113 \mathrm{~nm}$, respectively. In addition, the grating coupler exhibited a high alignment tolerance.
\end{abstract}

Keywords: grating coupler; integrated optics; lithium niobate thin film; 3D-FDTD

\section{Introduction}

The emergence of lithium niobate on an insulator (LNOI) has greatly promoted the development and progress of integrated optics devices [1,2]. The high refractive index contrast between $\mathrm{LN}$ and $\mathrm{SiO}_{2}$ in LNOI can shrink the photonic devices/circuits and enhance the remarkable optical properties of LN [3-6]. Due to its extraordinary nonlinearity and excellent electrooptical properties, LNOI can be used in a variety of expandable on-chip devices to provide nonlinear wavelength conversion and high-speed optical modulation [7-9]. At present, it is very important to improve the coupling efficiency between an LNOI waveguide and fiber. However, the mode mismatch between optical fiber mode and thin film material makes direct alignment coupling inefficient. A grating coupler is an effective way to solve the coupling problem between an LNOI waveguide and optical fiber [10-12]. A grating coupler has many advantages, such as being able to be positioned anywhere on the chip, a large alignment tolerance, and no requirement for end face polishing.

Silicon nitride $\left(\mathrm{Si}_{3} \mathrm{~N}_{4}\right)$ has a wide transparent spectrum and high compatibility with the standard complementary metal oxide semiconductor technology $[13,14]$. It is difficult to etch directly on LN. However, this situation can be avoided by using $\mathrm{Si}_{3} \mathrm{~N}_{4}$ strip loading. $\mathrm{Si}_{3} \mathrm{~N}_{4}$ strip-loaded LNOI can make use of the properties of $\mathrm{Si}_{3} \mathrm{~N}_{4}$ and LN, leading to heterogeneous photonic devices. Various photonic devices have been reported in $\mathrm{Si}_{3} \mathrm{~N}_{4}$ strip-loaded LNOI, including a multiplexer [15], a micro-ring resonator [16], and an electrooptic modulator [17]. A large bandwidth can be obtained by using $\mathrm{Si}_{3} \mathrm{~N}_{4}$ grating couplers, such as $\mathrm{Si}_{3} \mathrm{~N}_{4}$-on-SOI grating couplers [18,19]. Modeling and simulation are indispensable steps in preparing high-quality grating.

In this study, an $\mathrm{Si}_{3} \mathrm{~N}_{4}$ strip-loaded grating coupler on LNOI was studied and simulated based on the three-dimensional finite-difference time-domain method (3D-FDTD). The important parameters affecting the coupling efficiency of the grating coupler, including the grating period $(\Lambda)$, duty cycle $(D C=\omega / \Lambda$, where $\omega$ is the ridge width), the thickness 
of the $\mathrm{SiO}_{2}$ cladding layer $(T)$, the fiber position $x$ (distance between the grating edge and the fiber core in the $x$-axis, $L x$ ), the fiber position $y$ (distance between the center line of the grating and the fiber core in the $y$-axis, $L y)$, and the fiber angle $(\theta)$, were optimized, which provided guidance for improving the coupling efficiency of the grating couplers. The tolerance of the grating coupler was also carefully studied due to its great importance for the practical implementation of such a device.

\section{Device Design and Methods}

The structure of the $\mathrm{Si}_{3} \mathrm{~N}_{4}$ strip-loaded grating coupler on LNOI that was studied from the top to bottom layers included a $0.3-\mu \mathrm{m}$-thick $\mathrm{Si}_{3} \mathrm{~N}_{4}$ strip, a 0.5 - $\mu \mathrm{m}$-thick $\mathrm{x}$-cut singlecrystal LN thin film, an amorphous $\mathrm{SiO}_{2}$ cladding layer, and an $\mathrm{LN}$ substrate. The crosssectional diagrams of the grating coupler are shown in Figure 1. The fiber fundamental transverse electric mode $\left(\mathrm{TE}_{0}\right)$ was used as the light source to simulate the coupling process between the grating coupler and the optical fiber. Considering the single-mode operation, the small mode effective area, the optical power in the LN thin film, and the bending loss, the thickness of the $\mathrm{Si}_{3} \mathrm{~N}_{4}$ strip-loaded grating coupler was selected as $0.3 \mu \mathrm{m}$ [20], and it was fully etched. The thickness of the $\mathrm{LN}$ film was set to $0.5 \mu \mathrm{m}$. The parameters $\Lambda$, $D C, T, L x, L y$, and $\theta$ were varied to maximize the light coupling in the waveguide from the single-mode fiber.

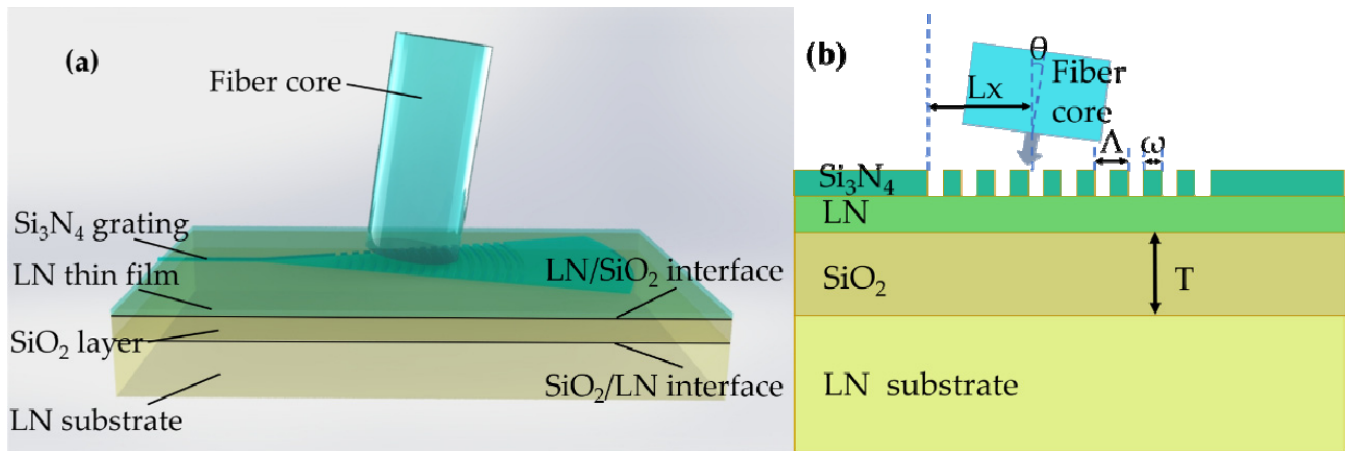

Figure 1. (a) The structure diagram, and (b) schematic cross-section of an $\mathrm{Si}_{3} \mathrm{~N}_{4}$ strip-loaded grating coupler on LNOI.

The mechanism of the grating coupler is as follows: the light of a single-mode fiber was coupled to the grating structure because of the diffraction effect of the grating coupler. When the input field mode was matched to the waveguide mode, the light could be effectively coupled from the single-mode fiber to the waveguide plane. The overlap integral between the input field mode and the waveguide mode could be increased with the optimization of the parameters of the grating coupler to reduce the mode mismatch between the waveguide optical device and the single-mode fiber [21]. The coupling efficiency was defined as the percentage of power converted from the source power to the waveguide plane.

After diffracting through the grating coupler, part of the beam from the fiber was reflected back to the fiber, and part was scattered to the $\mathrm{LN}$ cladding. At the $\mathrm{LN} / \mathrm{SiO}_{2}$ interface, part of the power was transmitted to the $\mathrm{SiO}_{2}$ cladding layer, and part of the power was reflected upwards and transmitted to the grating through the LN cladding layer again. The power was transmitted into the $\mathrm{SiO}_{2}$ cladding layer. At the $\mathrm{SiO}_{2} / \mathrm{LN}$ interface, part of the power that was lost was transmitted into the LN substrate, and part of the power was reflected and propagated upward through the $\mathrm{SiO}_{2}$ cladding to the $\mathrm{LN}$ cladding layer. Based on the commercial software Lumerical FDTD Solutions (Version: 8. 9.1584, ANSYS Inc., South Pittsburg, PA, USA) [22], the 3D-FDTD method under the condition of mess accuracy of $10 \mathrm{ppw}$ (the number of mesh points per wavelength) was used for simulation and optimization, and the perfectly matched layer (PML) boundary conditions were used to absorb the light emitted from the simulation area. For the FDTD solutions [23], based on the solution of the vector three-dimensional Maxwell equations, the 
FDTD method was used to grid the space step-by-step in time based on the time-domain signal to obtain the steady-state continuous wave, resulting in a wide band, and the unique material model could accurately describe the dispersion characteristics of the material in a wide band with embedded high speed. A high-performance computing engine could be used to obtain wide band multiwavelength results in one calculation, simulate any three-dimensional shape, and provide an accurate dispersion material model. For the PML [22], due to the limitations of the computer memory capacity and the calculation speed, the FDTD calculation could only be carried out in a limited area. In order to simulate the propagation process of an ultrasonic wave in a larger area, it was necessary to set the absorption boundary conditions at the boundary of the area to absorb the incident waves and avoid reflecting waves as much as possible. The most common absorption boundary condition was the PML absorption boundary, which could theoretically achieve complete absorption.

\section{Results and Discussion}

According to the Bragg phase matching condition, the resonant excitation of the coupled mode is carried out when Equation (1) is satisfied [24]:

$$
k \sin \theta=\beta+\frac{q \times 2 \pi}{\Lambda}
$$

In the expression, $k=\frac{2 \pi}{\lambda}$ is the wave number, $q$ is the diffraction order $(q=-1), \theta$ is the incident angle, $\beta=\frac{2 \pi n_{\text {eff }}}{\lambda}$ is the real part of the propagation constant, and $n_{\text {eff }}$ is the effective refractive index of the guided mode. The range of the grating period can be estimated by using the above equation.

The grating coupler is sensitive to the effective refractive index, which has to fulfill the inequality $n_{\mathrm{SiO}_{2}} \leq n_{e f f} \leq n_{\mathrm{LN}}$, where $n_{\mathrm{LN}}$ and $n_{\mathrm{SiO}_{2}}$ are the refractive indices of $\mathrm{SiO}_{2}$ (1.444) and $L N(2.138)$ [25], respectively. The fiber angle $\theta$, selected as $8^{\circ}$, can effectively avoid the second-order reflection that greatly reduces the coupling efficiency of the vertical grating coupler [26]. By substituting the inequality into Equation (1), the estimated range of $\Lambda$ for the optical fiber angle can be obtained as $\frac{\lambda}{2.138-\sin \theta} \leq \Lambda \leq \frac{\lambda}{1.989-\sin \theta}$. The range of $\Lambda$ is estimated to be $0.775 \mu \mathrm{m} \leq \Lambda \leq 1.188 \mu \mathrm{m}$.

In order to improve the coupling efficiency, the parameters of the grating coupler are analyzed and optimized. The thickness and the etching depth of the $\mathrm{Si}_{3} \mathrm{~N}_{4}$ strip-loaded grating coupler are set to $0.3 \mu \mathrm{m}$. Due to the polarization sensitivity of the grating coupler, the fundamental TE mode is used in the simulation. The parameters of the TE polarized grating coupler are simulated and optimized. The results are shown in Table 1 . The optimized coupling efficiency at a wavelength of $1.55 \mu \mathrm{m}$ is $33.5 \%$.

Table 1. The optimized parameters of the $\mathrm{Si}_{3} \mathrm{~N}_{4}$ strip-loaded grating coupler at a wavelength of $1.55 \mu \mathrm{m}$.

\begin{tabular}{cccccc}
\hline $\boldsymbol{\Lambda}(\mu \mathrm{m})$ & $\boldsymbol{D C}$ & $\boldsymbol{T}(\mu \mathrm{m})$ & $\boldsymbol{L x}(\mu \mathrm{m})$ & $\operatorname{Ly}(\mu \mathrm{m})$ & $\boldsymbol{\theta}\left({ }^{\circ}\right)$ \\
\hline 1.166 & 0.54 & 2 & 4.8 & 1 & 8 \\
\hline
\end{tabular}

The relationship between the coupling efficiency and the wavelength is shown in Figure 2. The coupling efficiency is half of the peak value when the wavelengths of light are 1.494 and $1.607 \mu \mathrm{m}$. The $-3 \mathrm{~dB}$ bandwidth is $113 \mathrm{~nm}$. The simulation results show that the $\mathrm{Si}_{3} \mathrm{~N}_{4}$ strip-loaded grating coupler on LNOI has a larger $-3 \mathrm{~dB}$ bandwidth compared with the silicon strip-loaded grating coupler on LNOI [27]. 


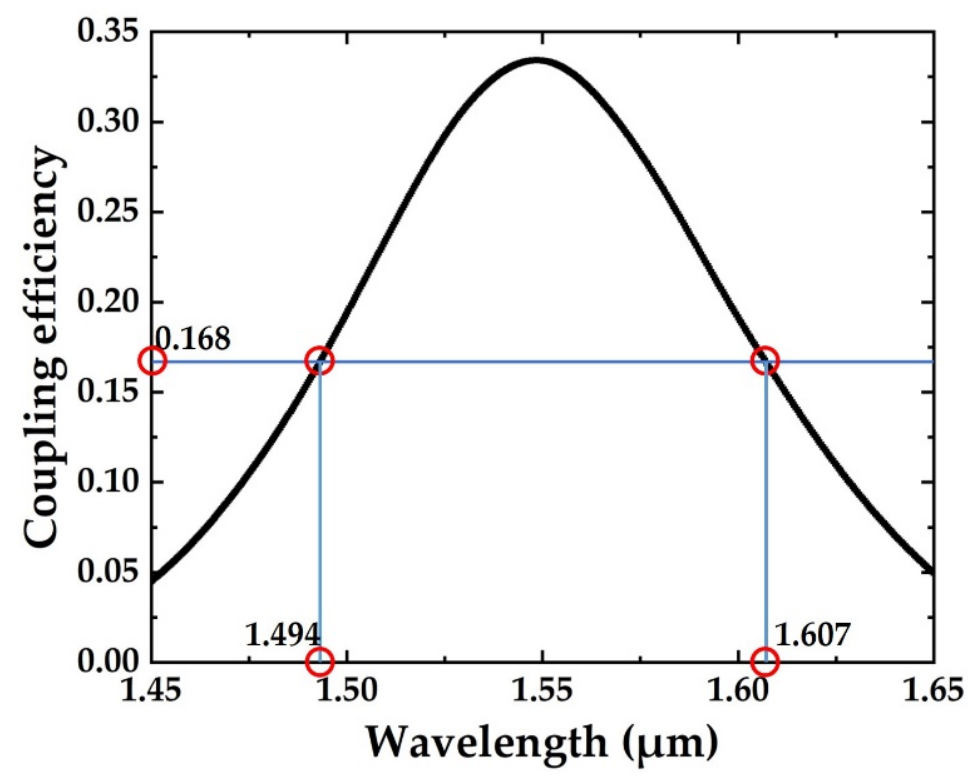

Figure 2. Coupling efficiency as a function of wavelength.

In this simulation, the influence of each parameter on the performance of the grating coupler is studied using the control variable method. During the simulation, except for the modification of the studied parameter, the other parameters are fixed at their optimized values.

The relationship between the coupling efficiency and the grating period is shown in Figure $3 \mathrm{a}$. When the grating period varies to $1.166 \mu \mathrm{m}$, the coupling efficiency reaches its maximum value. The coupling efficiency remains above $30 \%$ when the grating period deviates by $0.022 \mu \mathrm{m}$. The relationship between the coupling efficiency and the wavelength at different periods is shown in Figure 3b. The coupling efficiency at a wavelength of $1.55 \mu \mathrm{m}$ corresponds to the red circles in Figure 3a. The peak of the coupling efficiency is red-shifted when the period increases, and it moves in the opposite direction when the period decreases.
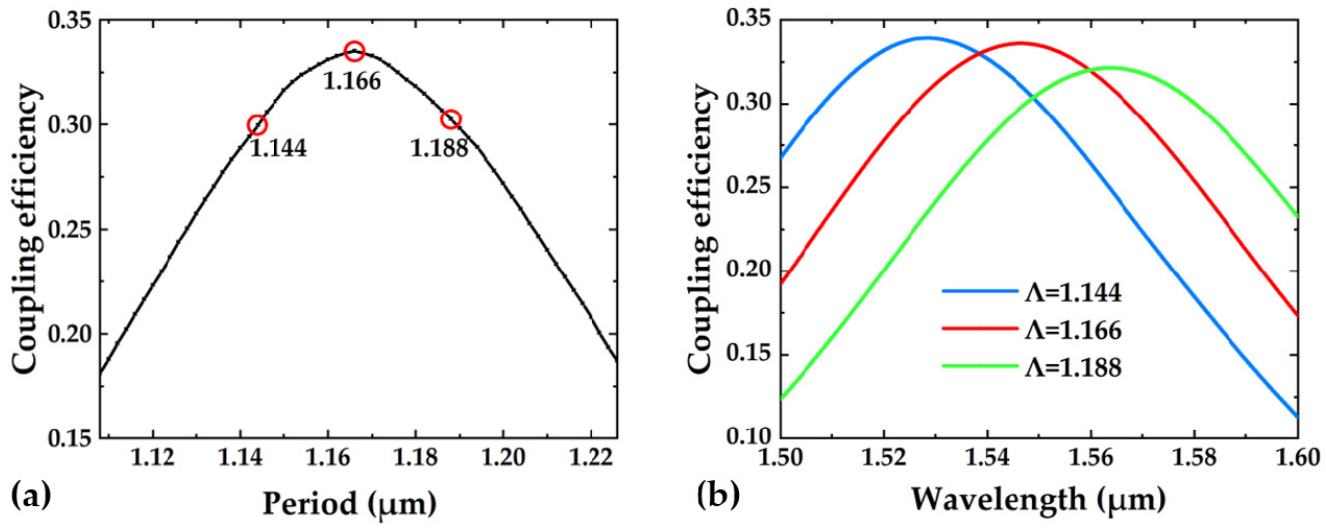

Figure 3. (a) Coupling efficiency as a function of the period. (b) Coupling efficiency as a function of the wavelength at different periods.

The relationship between the coupling efficiency and the duty cycle is shown in Figure $4 \mathrm{a}$. The coupling efficiency reaches a peak when the duty cycle varies to 0.54 . When the duty cycle deviates by 0.08 , it retains a coupling efficiency of more than $30 \%$ at a wavelength of $1.55 \mu \mathrm{m}$. Figure $4 \mathrm{~b}$ shows the variation of the coupling efficiency with wavelengths for different duty cycles. The coupling efficiency at a wavelength of $1.55 \mu \mathrm{m}$ in Figure $4 \mathrm{~b}$ corresponds to the red circles in Figure $4 \mathrm{a}$. The peak of the coupling efficiency 
is red-shifted when the duty cycle increases, and it moves in the opposite direction when the duty cycle decreases.
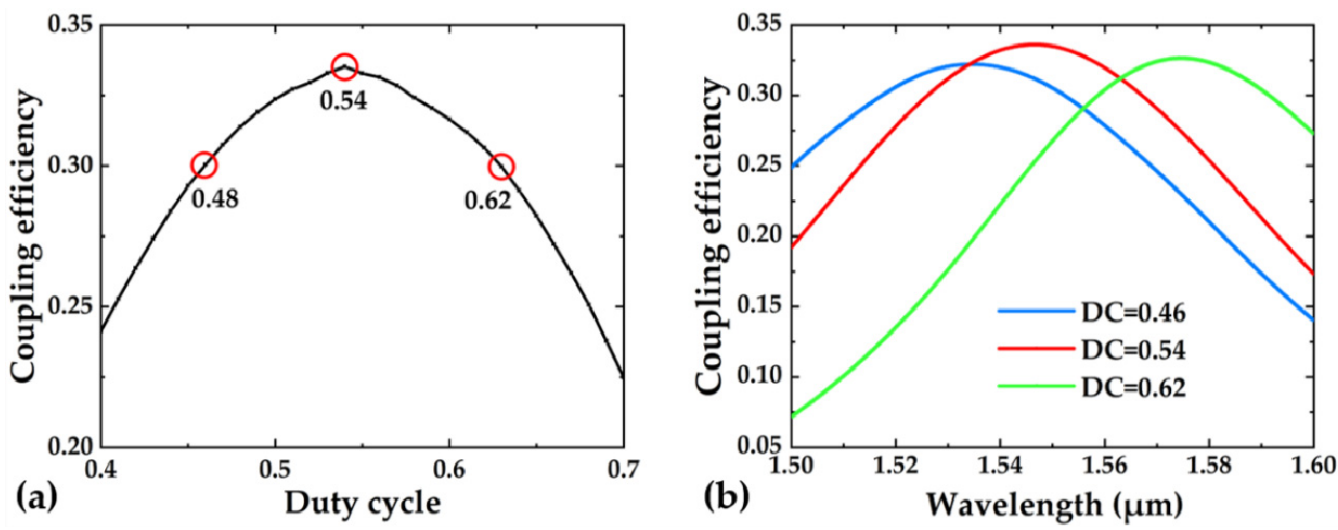

Figure 4. (a) Coupling efficiency as a function of the duty cycle. (b) Coupling efficiency as a function of the wavelength at different duty cycles.

The relationship between the coupling efficiency and the $\mathrm{SiO}_{2}$ cladding layer thickness is shown in Figure 5. The curve of the coupling efficiency oscillates periodically between the maximum and the minimum as the thickness of the $\mathrm{SiO}_{2}$ cladding layer increases. The periodic variation of the coupling efficiency stems from the constructive or destructive interference between the upward reflected light from the $\mathrm{LN} / \mathrm{SiO}_{2}$ interface and the $\mathrm{SiO}_{2} / \mathrm{LN}$ interface.

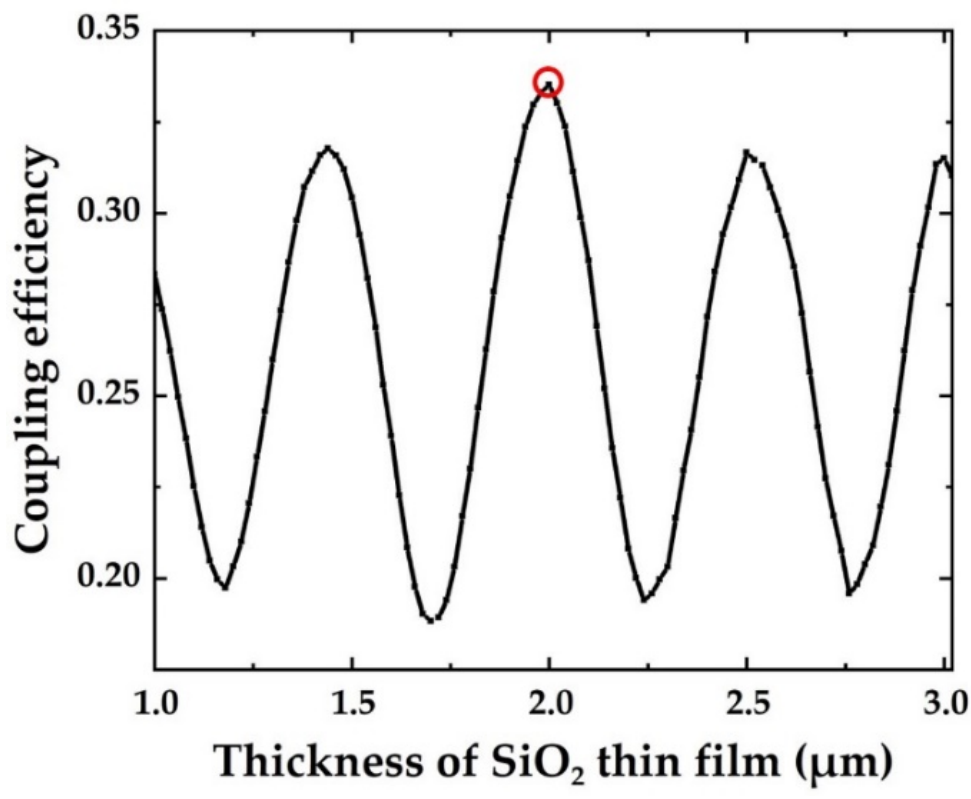

Figure 5. Coupling efficiency as a function of the $\mathrm{SiO}_{2}$ cladding thickness.

Figure $6 \mathrm{a}, \mathrm{b}$ shows the coupling efficiencies as functions of $L x$ and $L y$, respectively. Since the grating coupler is symmetrical in the $y$-direction, only half of $L y$ is simulated. The coupling efficiencies reach their peaks when $L x$ and $L y$ are set at $4.8 \mu \mathrm{m}$ and $1 \mu \mathrm{m}$, respectively. The coupling efficiency decreases faster when $L x$ decreases than when $L x$ increases. The coupling efficiency decreases to $30 \%$ when $L x$ is $3 \mu \mathrm{m}$ and $7.2 \mu \mathrm{m}$. When $L y$ is less than $5 \mu \mathrm{m}$, the coupling efficiency is almost unchanged. However, the coupling efficiency begins to decrease rapidly when $L y$ is $6 \mu \mathrm{m}$, while the coupling efficiency decreases sharply to $29 \%$. 
Figure 7a shows the relationship between the coupling efficiency and the fiber angle. The coupling efficiency is very sensitive to the change of the fiber angle. The coupling efficiency decreases very little when the fiber angle deviates by $1^{\circ}$. However, the coupling efficiency decreases rapidly when the fiber angle deviates by $2^{\circ}$. The peak of the coupling efficiency is red-shifted when the fiber angle decreases, and it moves in the opposite direction when the fiber angle increases.
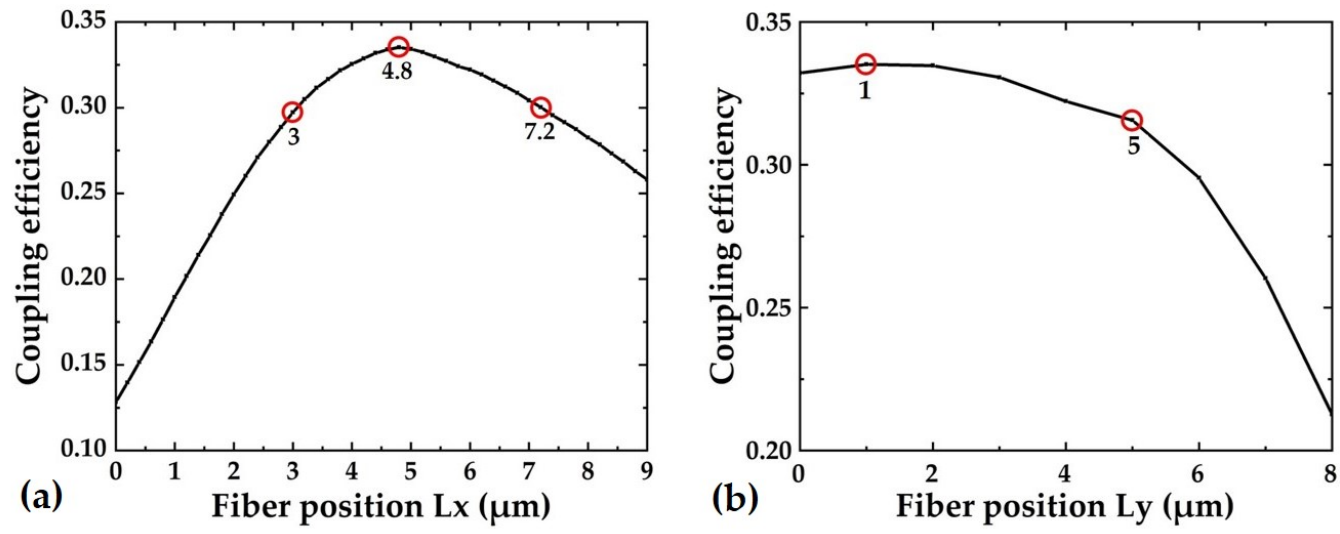

Figure 6. (a) Coupling efficiency as a function of $L x$. (b) Coupling efficiency as a function of $L y$.
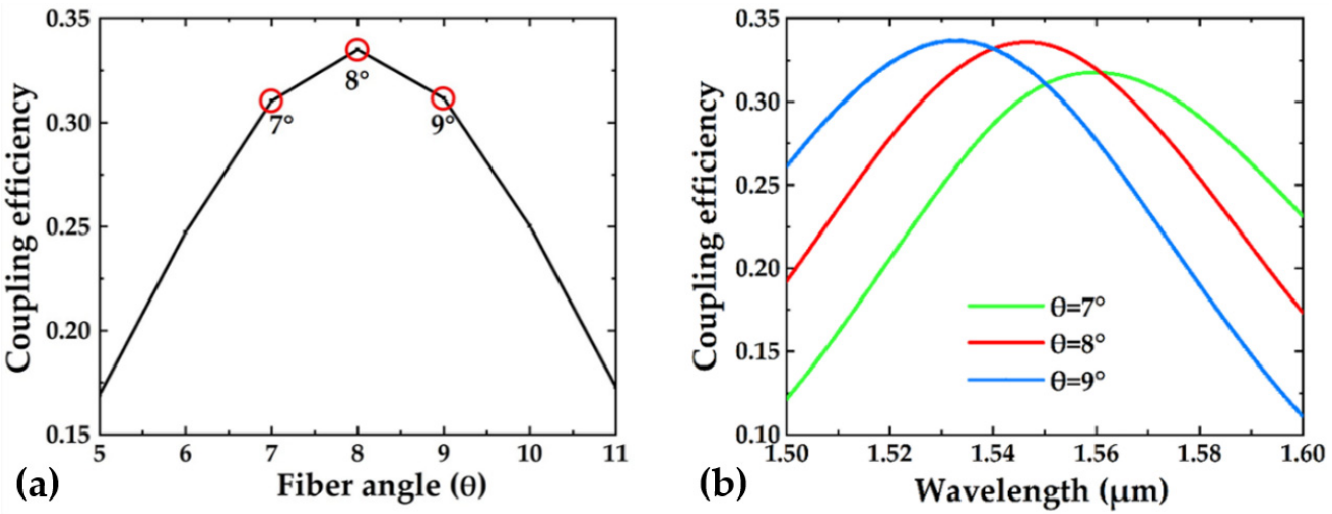

Figure 7. (a) Coupling efficiency as a function of the fiber angle. (b) Coupling efficiency as a function of the wavelength at different fiber angles.

Figure 8 shows the electric field distribution of the light wave. The in-coupled light formed an angle $\left(8^{\circ}\right)$ relative to the normal of the LN substrate. This angle allows the grating coupler to achieve near-vertical coupling in the waveguide plane at wavelengths of around $1.55 \mu \mathrm{m}$ while avoiding second-order reflection. The light from the optical fiber is mainly divided into three parts: some scatter upwards into the air due to reflection, some are coupled into the waveguide, and others are lost in the substrate.

Table 2 lists a comparison of the different types of grating couplers previously reported on and the coupler in this work. The chirped grating couplers and grating couplers using the bottom or top reflectors have higher coupling efficiencies than uniform grating couplers. In this work, the maximum coupling efficiency of the LNOI coupler using uniform $\mathrm{Si}_{3} \mathrm{~N}_{4}$ strip loading is $33.5 \%$, and the $-3 \mathrm{~dB}$ bandwidth is $113 \mathrm{~nm}$. It can be confirmed that the grating coupler is a reliable method for solving the coupling between the chip and the single-mode fiber, and a wide $-3 \mathrm{~dB}$ bandwidth can be obtained by using $\operatorname{Si}_{3} \mathrm{~N}_{4}$ strip loading. 


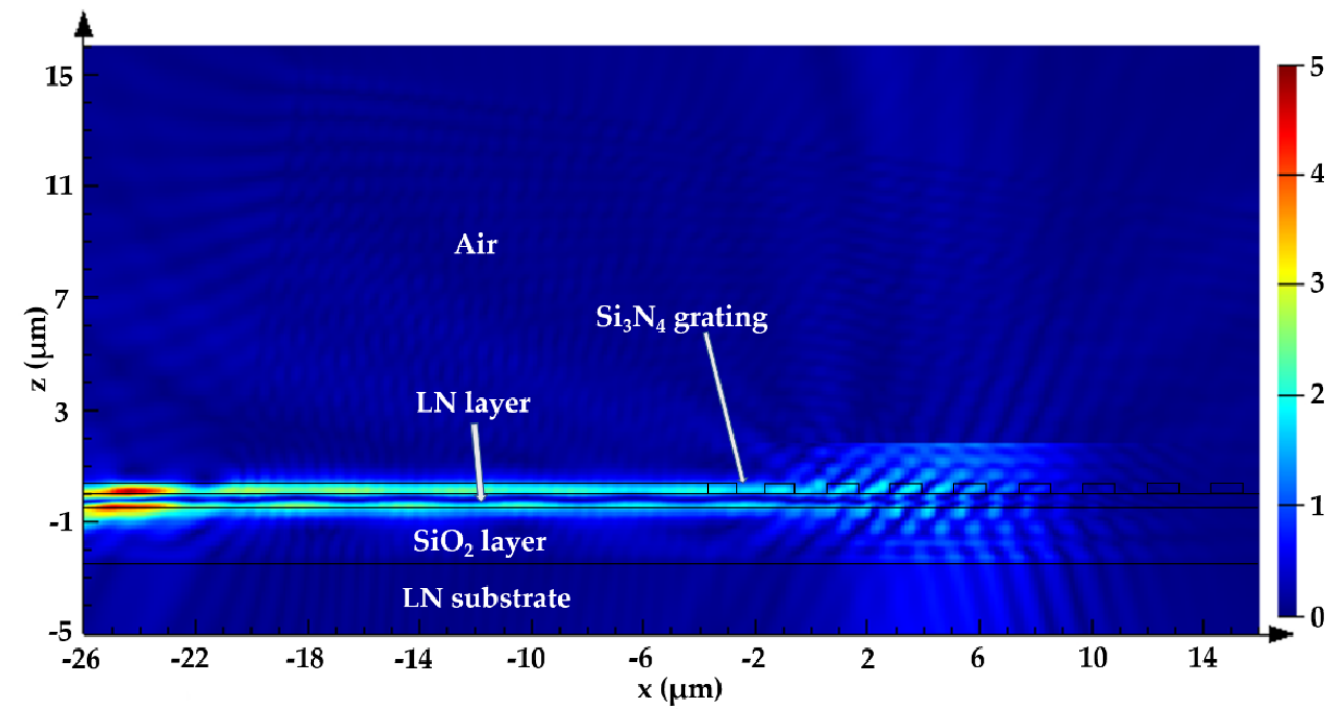

Figure 8. Electric field distribution of the light wave.

Table 2. A comparison of the reported grating couplers in this work.

\begin{tabular}{|c|c|c|c|c|}
\hline Grating Coupler Type & Features & Coupling Efficiency (\%) & Bandwidth (nm) & Ref \\
\hline $\mathrm{LN}$-on-SiO ${ }_{2}$ & Chirped grating coupler & $\begin{array}{c}43.7(\mathrm{TE}) \\
(1550 \mathrm{~nm})\end{array}$ & $48(-3 \mathrm{~dB})$ & [10] \\
\hline $\mathrm{Si}_{3} \mathrm{~N}_{4}$-on-SOI & Apodized grating coupler & $\begin{array}{l}79.4(\mathrm{TE}) \\
(1550 \mathrm{~nm})\end{array}$ & $80(-1 \mathrm{~dB})$ & [16] \\
\hline Si-on-LNOI & Polarization-independent & $\begin{array}{c}50.1(\mathrm{TE}) \\
(1550 \mathrm{~nm})\end{array}$ & $86(-3 \mathrm{~dB})$ & [17] \\
\hline LN-on-SiO ${ }_{2}$ & Chirped and apodized grating coupler & $\begin{array}{c}83.2(\mathrm{TE}) \\
(1536 \mathrm{~nm})\end{array}$ & $82(-3 \mathrm{~dB})$ & [28] \\
\hline LN-on- $\mathrm{SiO}_{2}$ & Integrated coupler and filter & $\begin{array}{c}14.5(\mathrm{TE}) \\
(1550 \mathrm{~nm})\end{array}$ & $80(-3 \mathrm{~dB})$ & [29] \\
\hline $\mathrm{Si}-\mathrm{SiO}_{2}-\mathrm{LN}$ & Fully etched grating & $\begin{array}{c}53.7(\mathrm{TE}) \\
(1550 \mathrm{~nm})\end{array}$ & $102(-3 \mathrm{~dB})$ & [30] \\
\hline LN-on-SiO ${ }_{2}$ & Metal bottom reflector & $\begin{array}{c}45.7(\mathrm{TE}) \\
(1553.5 \mathrm{~nm})\end{array}$ & $30(-1 \mathrm{~dB})$ & [31] \\
\hline Si-on-SiO 2 & $\begin{array}{l}\text { Uniform grating with } \\
\text { upper reflector }\end{array}$ & $\begin{array}{c}89.4 \text { (TE) } \\
(\sim 1550 \mathrm{~nm})\end{array}$ & $96(-3 \mathrm{~dB})$ & [32] \\
\hline $\mathrm{Si}_{3} \mathrm{~N}_{4}$-on-LNOI & Strip-loaded uniform grating & $\begin{array}{l}33.5(\mathrm{TE}) \\
(1550 \mathrm{~nm})\end{array}$ & $113(-3 \mathrm{~dB})$ & This work \\
\hline
\end{tabular}

\section{Conclusions}

In this work, a 3D-FDTD simulation technique was used to systematically study the performance of an $\mathrm{Si}_{3} \mathrm{~N}_{4}$ strip-loaded grating coupler on LNOI. The light was coupled vertically into the LNOI waveguide from a single-mode fiber. The parameters $\Lambda, D C, T, L x$, $L y$, and $\theta$ were analyzed and optimized to be $1.166 \mu \mathrm{m}, 0.54,2 \mu \mathrm{m}, 4.8 \mu \mathrm{m}, 1 \mu \mathrm{m}$, and $8^{\circ}$, respectively. At wavelengths of around $1.55 \mu \mathrm{m}$, the maximums of the coupling efficiency and the $-3 \mathrm{~dB}$ bandwidth were $33.5 \%$ and $113 \mathrm{~nm}$, respectively. The relationship between the parameter tolerance and the coupling efficiency of the grating couplers was discussed. Larger tolerances greatly reduced the requirements for manufacturing accuracy. Our simulation results for the grating couplers will provide useful guidance for the fabrication of similar optical devices.

Author Contributions: H.H. conceived the original idea; F.Y. carried out the simulations and wrote the manuscript; and H.F. and B.X. contributed the useful and deep discussions, analyzed the data, and modified the manuscript. All authors have read and agreed to the published version of the manuscript.

Funding: This work was supported by the National Natural Science Foundation of China (12105190) and Shenzhen Science and Technology Planning (JCYJ20190813103207106). 
Data Availability Statement: Data will be made available upon request.

Conflicts of Interest: The authors declare no conflict of interest.

\section{References}

1. Poberaj, G.; Hu, H.; Sohler, W.; Gunter, P. Lithium niobate on insulator (LNOI) for micro-photonic devices. Laser Photonics Rev. 2012, 6, 488-503. [CrossRef]

2. Boes, A.; Corcoran, B.; Chang, L.; Bowers, J.; Mitchell, A. Status and Potential of Lithium Niobate on Insulator (LNOI) for Photonic Integrated Circuits. Laser Photonics Rev. 2018, 12, 1700256. [CrossRef]

3. Wang, C.; Zhang, M.; Chen, X.; Bertrand, M.; Shams-Ansari, A.; Chandrasekhar, S.; Winzer, P.; Lončar, M. Integrated lithium niobate electro-optic modulators operating at CMOS-compatible voltages. Nature 2018, 562, 101-104. [CrossRef]

4. Han, H.; Cai, L.; Hu, H. Optical and structural properties of single-crystal lithium niobate thin film. Opt. Mater. 2015, 42, 47-51. [CrossRef]

5. Xu, M.; He, M.; Zhang, H.; Jian, J.; Pan, Y.; Liu, X.; Chen, L.; Meng, X.; Chen, H.; Li, Z.; et al. High-performance coherent optical modulators based on thin-film lithium niobate platform. Nat. Commun. 2020, 11, 3911-3917. [CrossRef]

6. Cai, L.; Han, H.; Zhang, S.; Hu, H.; Wang, K. Photonic crystal slab fabricated on the platform of lithium niobate-on-insulator. Opt. Lett. 2014, 39, 2094-2096. [CrossRef]

7. Luo, K.-H.; Brauner, S.; Eigner, C.; Sharapova, P.R.; Ricken, R.; Meier, T.; Herrmann, H.; Silberhorn, C. Nonlinear integrated quantum electro-optic circuits. Sci. Adv. 2019, 5, eaat1451. [CrossRef]

8. Li, M.; Ling, J.; He, Y.; Javid, U.A.; Xue, S.; Lin, Q. Lithium niobate photonic-crystal electro-optic modulator. Nat. Commun. 2020, 11, 4123-4130. [CrossRef]

9. Wang, C.; Zhang, M.; Yu, M.; Zhu, R.; Hu, H.; Loncar, M. Monolithic lithium niobate photonic circuits for Kerr frequency comb generation and modulation. Nat. Commun. 2019, 10, 978-983. [CrossRef]

10. Cai, L.; Piazza, G. Low-loss chirped grating for vertical light coupling in lithium niobate on insulator. J. Opt. 2019, $21,065801$. [CrossRef]

11. Han, H.; Xiang, B. Grating Coupler Design for Vertical Light Coupling in Silicon Thin Films on Lithium Niobate. Crystals 2020, 10, 850. [CrossRef]

12. Chen, Z.; Peng, R.; Wang, Y.; Zhu, H.; Hu, H. Grating coupler on lithium niobate thin film waveguide with a metal bottom reflector. Opt. Mater. Express 2017, 7, 4010-4017. [CrossRef]

13. Romero-García, S.; Merget, F.; Zhong, F.; Finkelstein, H.; Witzens, J. Silicon nitride CMOS-compatible platform for integrated photonics applications at visible wavelengths. Opt. Express 2013, 21, 14036-14046. [CrossRef]

14. Ahmed, A.N.R.; Mercante, A.; Shi, S.; Yao, P.; Prather, D.W. Vertical mode transition in hybrid lithium niobate and silicon nitride-based photonic integrated circuit structures. Opt. Lett. 2018, 43, 4140-4143. [CrossRef]

15. Liu, Y.; Huang, X.; Li, Z.; Guan, H.; Yu, H.; Wei, Q.; Fan, Z.; Han, W.; Li, Z. On-chip four-mode (de-)multiplexer on thin film lithium niobite-silicon rich nitride hybrid platform. Opt. Lett. 2021, 46, 3179-3182. [CrossRef] [PubMed]

16. Ahmed, A.N.R.; Shi, S.; Zablocki, M.; Yao, P.; Prather, D.W. Tunable hybrid silicon nitride and thin-film lithium niobate electro-optic microresonator. Opt. Lett. 2019, 44, 618-621. [CrossRef]

17. Zhang, P.; Huang, H.; Jiang, Y.; Han, X.; Xiao, H.; Frigg, A.; Nguyen, T.G.; Boes, A.; Ren, G.; Su, Y.; et al. High-speed electro-optic modulator based on silicon nitride loaded lithium niobate on an insulator platform. Opt. Lett. 2021, 46, 5986-5989. [CrossRef]

18. Sacher, W.D.; Huang, Y.; Ding, L.; Taylor, B.J.F.; Jayatilleka, H.; Lo, G.-Q.; Poon, J.K.S. Wide bandwidth and high coupling efficiency Si_3N_4-on-SOI dual-level grating coupler. Opt. Express 2014, 22, 10938-10947. [CrossRef]

19. Doerr, C.R.; Chen, L.; Chen, Y.-K.; Buhl, L.L. Wide Bandwidth Silicon Nitride Grating Coupler. IEEE Photonics-Technol. Lett. 2010, 22, 1461-1463. [CrossRef]

20. Han, H.; Yang, F.; Liu, C.; Jiang, Y.; Xiang, B.; Ruan, C. High-performance electro-optical Mach-Zehnder modulator in silicon nitride-lithium niobate thin film hybrid platform. Opt. Express 2022. in submit.

21. Cheng, L.; Mao, S.; Li, Z.; Han, Y.; Fu, H.Y. Grating Couplers on Silicon Photonics: Design Principles, Emerging Trends and Practical Issues. Micromachines 2020, 11, 666. [CrossRef]

22. Solutions, L. Available online: http:/ / www.lumerical.com/ (accessed on 18 November 2021).

23. Shibayama, J.; Ando, R.; Yamauchi, J.; Nakano, H. A 3-D LOD-FDTD Method for the Wideband Analysis of Optical Devices. J. Lightwave Technol. 2011, 29, 1652-1658. [CrossRef]

24. $\mathrm{Mu}, \mathrm{X}$;; Wu, S.; Cheng, L.; Fu, H.Y. Edge Couplers in Silicon Photonic Integrated Circuits: A Review. Appl. Sci. 2020, 10, 1538. [CrossRef]

25. Schlarb, U.; Betzler, K. A generalized sellmeier equation for the refractive indices of lithium niobate. Ferroelectrics 1994, 156, 99-104. [CrossRef]

26. Vivien, L.; Pascal, D.; Lardenois, S.; Marris-Morini, D.; Cassan, E.; Grillot, F.; Laval, S.; Fédéli, J.-M.; Melhaoui, L.M. Light injection in SOI microwaveguides using high-efficiency grating couplers. J. Lightwave Technol. 2006, 24, 3810-3814. [CrossRef]

27. Ma, X.; Zhuang, C.; Zeng, R.; Coleman, J.J.; Zhou, W. Polarization-independent one-dimensional grating coupler design on hybrid silicon/LNOI platform. Opt. Express 2020, 28, 17113-17121. [CrossRef] [PubMed] 
28. Chen, Z.; Ning, Y.; Xun, Y. Chirped and apodized grating couplers on lithium niobate thin film. Opt. Mater. Express 2020, 10, 2513-2521. [CrossRef]

29. Baghban, M.A.; Schollhammer, J.; Errando-Herranz, C.; Gylfason, K.B.; Gallo, K. Bragg gratings in thin-film LiNbO_3 waveguides. Opt. Express 2017, 25, 32323-32332. [CrossRef]

30. Jian, J.; Xu, P.; Chen, H.; He, M.; Wu, Z.; Zhou, L.; Liu, L.; Yang, C.; Yu, S. High-efficiency hybrid amorphous silicon grating couplers for sub-micron-sized lithium niobate waveguides. Opt. Express 2018, 26, 29651-29658. [CrossRef]

31. Chen, B.; Ruan, Z.; Hu, J.; Wang, J.; Lu, C.; Lau, A.P.T.; Guo, C.; Chen, K.; Chen, P.; Liu, L. Two-dimensional grating coupler on an X-cut lithium niobate thin-film. Opt. Express 2021, 29, 1289-1295. [CrossRef]

32. Zhang, Z.; Shan, X.; Huang, B.; Zhang, Z.; Cheng, C.; Bai, B.; Gao, T.; Xu, X.; Zhang, L.; Chen, H. Efficiency Enhanced Grating Coupler for Perfectly Vertical Fiber-to-Chip Coupling. Materials 2020, 13, 2681. [CrossRef] [PubMed] 